\title{
Boundary objects in offshore platform design: the connections between individual and collective dimensions
}

\author{
Renato Porthun ${ }^{a}$, Ricardo Manfredi Naveirob, Francisco José de Castro Moura Duarte ${ }^{b}$ \\ 'Navy of Brazil \\ ${ }^{b}$ Federal University of Rio de Janeiro
}

e-mails: renato.porthun@casnav.mar.mil.br; ricardo.naveiro@poli.ufri.br; ficmduarte@gmail.com

\begin{abstract}
The purpose of this paper is to analyze teamwork performance in offshore platform design, discussing the contribution of design intermediary objects, also called "boundary objects", to establish a connection between collective and individual approaches in design activities. These boundary objects allow participants to conceive and maintain a shared conception of a problem in which knowledge is structured in applied situations during the decision making process. The nature of the design process is presented stressing the two complementary dimensions - individual and collective - that participants need to integrate to find a feasible solution to a problem. The role played by graphical representations in the design process is discussed, and the association to the concept of "boundary objects" is also presented. An application to a real situation on offshore platform design is described, showing how a specific boundary object - the electronic mock-up - strongly influence how participants relate, identify the tasks to be accomplished, and make decisions accordingly. The conclusion emphasizes some "boundary objects" features and suggests some issues for future development.
\end{abstract}

Keywords: design process, CAD systems, boundary objects, 3D model, design review.

\section{Introduction}

The design process uses several forms of visual language in the conception of an artifact. The visual language integrated to other forms of communication allows the contextualization of problems, and the translation of design soluctions to different people with different technical background. The artifact creation works intensively with graphical representation; the graphic representation is a tool to achieve design solutions and a means to translate these solutions to participants of a design team.

Besides the visual representations the design process is characterized by the creation of several boundary objects that enable the articulation among different disciplines involved in the design process. The nature of these boundary objects varies from open objects that do have ambiguity as they are more close to the design discourse to more specific ones which is the case of technical drawings and electronic mock-up.

The project activity is a collective negotiation and decision-making process in which communication among its several participants is one of its essential aspects. It is commonplace that communication among actors in the initial stages of a design process is a notoriously difficult and recurrent problem. Mistakes and inconsistencies originated from lack of communication among the design team are identified only at more advanced stages of the process, which implies in wasting time and incouring in extra costs to solve them. Communication problems are identified when project participants do not understand specifications, assertions, points of view, and knowledge accumulated by other members of the team.

As stressed by Bucciarelli (1988), these problems are related to the difficulties of communication among the different object worlds constituent of each project. Object worlds are better defined as universes of competences, that is, environments of technical specialization, with its own dialects and symbols, as well as models and metaphors for representation of abstract solutions. Designers face and solve their challenges of design according to their universes of specialization and dislocate themselves from their competence areas just a part of the total time of design.

In order to surpass these communication problems among a design team, computers are been used to to support design activities. In the past, the role played by computer tools in the design process was restricted to make drawings, do calculations and make analysis. Nowadays, Computer-Aided Design (CAD) systems follow the trend of incorporating knowledge into new applications. 
Modern CAD systems are feature based and embody knowledge in some domains. This permits to make evaluations while designing and assessing product manufacturability and assemblability. They can also be tailored to incorporate companies' current practices in their evaluation tasks. New generation of CAD systems can embody companies' current practices in the evaluation of new design ideas, verifying their preliminary feasibility. These new systems embody knowledge retrieved from former projects conveying relevant knowledge to designers. Some CAD systems allow collaborative work and the simultaneous access from participants, permitting cooperation and cognitive synchronization in decision making inside the design team.

A very important feature observed in brand new CAD systems is the possibility of usability assessment, using the electronic mock-up in off-shore platform design. This issue will be explored in the case study described in section 4 .

\section{Characterization of design activity}

Design is a complex activity. Problems faced by architects and engineers are ill structured and incomplete. Design is a knowledge-based process in which data, information and knowledge are processed simultaneously by a team of architects and engineers involved during the lifecycle of a product. It is a knowledge-driven activity in which requirements and constraints are transformed in a product description. The design process involves a great deal of knowledge accumulated by engineers and technicians during their professional life. Knowledge sources vary from formal education to individual experience, including knowledge derived from similar cases. Defining a cognitive structure for a design problem and its solutions is a knowledge-based learning process that involves practical knowledge and theoretical assets as well.

Design can be considered as pertaining to the class of open problems, that is, a class in which the constraints are not capable of entirely delimiting the space of solutions. That demands from the designer an effort to diminish the number of degrees of freedom in the search for a solution; which, in practice, represents a work of structuring the problem as far as the design progression occurs.

Engineers use basically two types of knowledge when creating new products: procedural and declarative knowledge. The first one is a type of knowledge expressed by procedures in organizational life, while declarative knowledge refers to more descriptive knowledge represented by equations, logical relations, or agents in new programming languages. This subject takes us to the distinction between theory and practice or know how versus know that. Theory refers to domain models, causal explanations or rules that explain certain phenomenon, types of knowledge normally acquired by formal education.

Practical knowledge refers to something that can be acquired from people doing efficiently a given task (human experts). The notion of practical knowledge is particularly relevant in learning because it has been observed for centuries that some knowledge needs apprenticeship (i.e., practice) to be learnt whereas another does not require such practice (CLANCEY, 1995). This discussion matches the situation observed in people involved with conception, in which design knowledge cannot be assimilated without practice.

The distinction between tacit and explicit is also important whereas we believe that any kind of knowledge can be made explicit or implicit depending on the circumstances, the persons and the society. Design is a social process where the acquisition and validation of the "know how" are two central issues within a project team in which individual tacit knowledge must be shared and transformed in something understandable by participants.

Design practice encompasses a series of creative activities such as artifact planning, product development, product synthesis and problem solving. Moreover, design involves an incremental learning process as an intrinsic part of designers' activities. The design process involves a typical sequence of steps in which the degree of uncertainty diminishes as the work progress, and the design progression can be viewed as a collection of successive states in which abstract ideas arrive to an embodied product.

Design is also seen as something with a great deal of innovation. However, in companies, the current design practice is mostly concentrated in the modifications and in the incremental improvements of current products. Some projects have a high innovative content, but most of the projects follow a different pattern, where innovation is not high. In these cases the artifact structure is unknown and emerges from the design activity itself. The design process is carried out in a planned way, in order to keep design activities consistent with the goals.

The classes of design commonly found in industry are adaptative design and variant design, which involve the use of known strategies, or established design plans to arrive to new solutions. In these cases, the problem decomposition strategy and some classes of solution are already known. In other words, the initial perception of the product structure is known and the disciplines needed to solve the design problems are already identified, as, for example, the case of designing townhouses and apartment-buildings. However, there is always some particularity in the design constraints, and different types of knowledge are always required in the design activity.

Design and learning are closely related activities where finding a new solution involves the search and acquisition 
of new knowledge. At preliminary steps of the design progression, a way to understand and to structure a design problem is to retrieve former design cases and design plans to form an abstract knowledge that can be further explored, in the spirit of case-based reasoning (TANG, 2001; KOLODNER, 1983). It is an inductive learning process that includes assimilation of new knowledge in a body of known and organized knowledge for future use. The information gathered in former projects is reshaped and reorganized, allowing engineers and architects to generalize; and abstract ideas that are explicit in particular situations can be used in analogous situations.

Designing a product involves the perception of the artifact structure that dynamically changes along the design progression, and also the translation of each state into the generation of new ideas. The artifact attributes captured by participants, and their interrelations, permit the clarification of the organization of design tasks accordingly with the design state and with the participant's role. The way in which participants capture artifact attributes is context-dependent because each person builds an interpretative context of the artifact that links their universe of specialization with the collective common goal. Participants think and work according to instrumental norms grounded in technical expertise. The object itself strongly influences how participants relate and identify the tasks to be accomplished (BUCCIARELLI, 1988).

The missing of information that happens in all engineering projects is surpassed by individual interactions that take place among participants of a design team. This fact stresses the need to support design teams in their decision process with technical resources that allow the integration of different viewpoints and also for the building of a common context for the project.

On the other hand, the design of technological artifacts can be characterized as a cognitive activity. Many researchers of the communities of cognitive ergonomics and psychology try to understand the nature of design expertise and to evaluate computer tools for supporting the design process. This way of approaching the design activity enhances the intellectual activities of problem solving and the strategies used by designers to reduce the complexity of design tasks (KARSENTY; BREZILLON, 1995). Thus, the main issues addressed in this paper are the mental mechanisms of association, decomposition and prototyping and their relations with external representations of the artifact.

In this article it is analysed the role of external representations in the project of an offshore petroleum platform, here defined as boundary objects. The boundary objects are considered by Vinck and Laureillard (1995) as coordinator drivers within the design process and, under this conceptualization, they concentrate their analysis on the nature and the role of boundary objects, mainly constituted of industrial diagrams and drawings, supposed to be the communication vectors among participants and different universes of specialization. These objects improve exchanges and permit the expression and understanding of different points of view. Once the project is shared among distinct designers, the circulation and sharing of these objects facilitates the construction of a collective action.

\section{Individual and collective dimensions}

As stated before, design is a social process, as underlined by the literature on communities of practice (BROWN; DUGUID, 1991; WENGER, 1998) and on design science (BUCCIARELLI, 1994; NAVEIRO, 2001). In this way, design is considered much more effective communication and collaboration, an environment for negotiation and decision in which members have a shared understanding, knowing what is relevant to communicate and how to present information in useful ways. The collective dimension is related to the interactions that occur among designers, while the social dimension encompass the relations and iterations with the other project actors (MARTIN, 1998)

A design team is a group of people in a work situation that involves multiple individuals working together in a planned way and in tasks that are related together. There is some agreement that design team work is a kind of "cooperative work" in which a set of relatively autonomous and non hierarchical coordinated activities is established, characterized by shared responsibilities. It is also referred as people engaged in incessant and direct communication performing tasks linked to the production of a particular product or service.

In contrast to the spontaneous linking of interrelated production processes, work relationships in design are characterized by being planned or rather premeditated (BANNON; SCHMIDT, 1991). In a design team participants are acquainted with design methodology and project goals, which define the accomplishment of some generic tasks to solve design problems (CHANDRASEKARAN, 1988). Design tasks are linked to procedures, generally used by engineers as frames to construct a genuine strategy tailored to the specificity of a given situation. In this sense, there are some planned collective activities in a design team that are adapted for each case or each design step, doesn't mattering the nature or the type of the project.

On the other hand, the project is also characterized by its individual perspective. In the individual perspective of the design, that is, in the individual practice of design, it is very important that the drawing exists as a work element capable of synthesizing and recording the creative act. The recording of what was created in any artificial environment allows the designer to free his short term memory for the generation of other alternatives. 
These two approaches in understanding the nature of the design process - collective and individual - are complementary. The process of designing an artifact is normally conducted by a team of professionals. Each specialist plays a specific role within the team and, simultaneously, is obliged to negotiate constraints and requirements with other specialists to arrive to feasible solutions. Considering computers to support design activities one must take into account these two aspects of the design activity (NAVEIRO, 1997).

The tasks can be conducted in a distributed manner by semi-autonomous professionals that plan their own strategies and change their behavior as the circumstance's change, matching the situation found in a design team, in which participants have their own specialization (architecture, facilities, etc.) interconnected by the project goals and project constraints. The communication process among a design team assumes a shared understanding of information, which is not found in groups with different backgrounds or belonging to different organizations.

A design team in the Engineering \& Construction sector is a group of experts in several domains with similar backgrounds cooperating in a common goal, thus building an interpretative context of problems and crossing the border between different disciplines are part constituent of design tasks, and the key issues faced by engineers. The design arena, a place to set up collective activities, is much more an environment for negotiation of constraints and decision making, where the identification of the tasks and the relationships between them allow tackling the domains and the role to be played by each participant. The routine issues addressed in supporting a team are how to manage and control the design information state, how to share the correct information, and how to deliver design information in the correct time.

\section{The boundary objects}

Designers face and solve their challenges according to their universes of specialization and are apart from their areas of competence just part of the total time of design. The attributes of the artifact captured by each participant are different and in tune with the specialization of each member of the design team. This imposes to each participant create interfaces with other contexts that influence his specific universe of competence allowing participants to cross the border between disciplines and building a common context for the project.

A design discourse is created to promote the reconciliation among the several universes of specialization, a sort of design "language" composed by several means of communication. Sketches, drawings, diagrams, design graphics, equations, physical and electronic mock-ups are part constituent of design "language", permitting the integration of spatial argumentation in the design discourse.

In this paper, these representations are considered as boundary objects, defined as means of representation of designers intention in a collective creative process, translators and carriers of ideas in the conception phase (VINCK, [199-?] década provável). Boundary objects are used to describe and analyze the design activity; they also reveal the relations among participants of a project team, as well as the activities carried out by them. In a second approach, boundary objects are defined as a means of materialization of practices, habits, conventions, and actors' know-how.

The theoretical fundaments related to the boundary objects consider that, from the objects manipulated during the conception activity, it is possible to analyze the design process rationale and the product development. Theses objects are inclined to improve the quality of the interaction among participants, permitting the expression of different points of view and the collective action construction. The boundary objects are studied by Vinck and Laureillard (1995) as coordination elements within the design process. They are classified in commissioning or mediation objects according to their coordination capacity; and in closed or open objects according to their possibility of being modified.

In situations in which the object user thinks and acts according to the designer's intention - without interpreting or transforming his intentions - it is supposed that the boundary objects impose to the user a way of interpreting or acting based on the object. In this case, the object is labeled as a "closed object," being characterized as a technical document which denotes a prescription, and not being able to be understood clearly by a multiplicity of the design team participants. The concept of "open objects" states that users are not completely tied to the object, providing its user with a certain margin of maneuver, which permits that participants of a multidisciplinary team work on the improvement of an idea.

In the realm of the collective perspective of the project, it is observed that participants develop their activities by means of the manipulation of the objects (physical or virtual), which constitute themselves as elements of language and communication in the mutual relationship among the design team. Besides their communicator role, the objects also model mutual relationships, behaviors and attitudes; acting as mediation enablers of the communication process (VINCK; JEANTET, 1995).

Graphic and textual documents are particularly interesting kinds of boundary objects. It is highlighted the role of graphic representations in the inter-professional cooperation which is developed around graphic objects. The graphic representations are closely connected to the design progression and project organization structure, 
being outcomes and ingredients of this activity. The graphic objects reflect the intentions, methods and restrictions taken in account by designers (VINCK; LAUREILLARD, 2003).

The boundary objects constitute indicators that help characterize the design process, by the simultaneous apprehension of the implicit content that interacts in a particular way in the collective reasoning dynamics. The design process is based fundamentally on the relations among participants, mediated by the objects that they manipulate; which play an essential role in the construction of a common referential among actors.

The design activity analysis based on boundary objects sheds light on the cognitive processes involved, and on the collective and socio-technical meanings employed to arrive to a certain solution. This belief is grounded in Vygotsky's theories that consider causal relationship between social interaction and the individual's cognitive development (VYGOTSKY, 1978). It is suggested that by interacting (directly or indirectly), participants can probably display abilities ahead of those displayed on their own. This means that the interactions established among participants enable knowledge to be shared and permit knowledge acquisition.

In summary, boundary objects enable:

- Creating more efficient interfaces for the communication among the participants, enabling them to socialize their universes of specialization involved in the design progression.

- Speeding the processes of negotiation and decision making established among the several actors of the project.

- Registering the decision-making process, thus enabling tracing design solutions.

\section{CAD systems and 3D models}

In the past, the role played by computer tools in the design process was restricted to make drawings, do calculations and make analysis. All these tasks were normally done after designers made their major decisions. At first, Computer-Aided Design (CAD) systems were used as a means to create drawings of an artifact, but they have evolved these last years. Nowadays, CAD systems follow the trend of incorporating knowledge into new applications.

Modern CAD systems are feature-based and embody knowledge in some domains. This permits to make evaluations while designing, i.e., an engineer for example, when conceiving a mechanism, can verify spatial interference between two moving parts by simulating their movement. Assessing product manufacturability and assembly merit is now common place in several commercial CAD systems. They can also be tailored to incorporate companies' current practices in their evaluation tasks. New generation of CAD systems can embody companies' current practices in the evaluation of new design ideas, verifying their preliminary feasibility. These new systems embody knowledge retrieved from former projects conveying relevant knowledge to designers, in a similar situation as the process of capitalizing knowledge in enterprises.

Generally CAD systems are software which enable the creation of geometry with a representation based in wire frame. They execute automatic drawings of groups of parts, validate and verify a design in accordance with specifications and rules, create engineering documents (technical drawings and lists of materials), generate automatically bi-dimensional drawings from the solid models and model surfaces as well.

Current CAD systems import and export data with different formats, calculate mass properties (among others) of the parts, possess parametric three-dimensional functions for modeling solids and facilitate design changes of the model producing multiple versions of a part. Besides this, they maintain a library of parts and assemblies, simulate mechanisms functioning without the need of a physical prototype, verify the kinematics and the interference between parts, and help the visualization of objects with the use of shades, rotation, transparency effects and texture, permitting the execution of images with photographic finishing before the construction of a physical model.

CAD systems can be classified according the modeling method or the range of applications. CAD systems with solid modeling are capable of generating three-dimensional objects embodied with material that can have physical properties, such as mass, gravity center and volume. Solid modeling CAD Systems allow the realization of Boolean operations such as addition, intersection and subtraction of geometric elements, permiting the final part generated to have a "historic" of the operations carried out for its construction, a kind of tree that contains several information about the construction of the part.

In the majority of the systems with solid modeling, this tree is at the user's disposal and he can alter one of the operations at any time, obtaining as result a different configuration for the designed part. On the other hand, the systems that use modeling by surfaces use mathematical formulations to generate the surfaces, permitting threedimensional models of extreme complex forms, where any point of the surface can be edited (directions X, Y, $\mathrm{Z}$ ) keeping the properties of the three-dimensional object (NAVEIRO, 2010).

CAD systems can be classified by the grade of coverage provided the system. There are systems that cover several technical domains with generic graphical resources that can be applied to different project disciplines; they are able to make technical drawings in several domains: architectural, mechanical, electrical, etc. There are others focused in certain domains, and with specific features to solve problems 
in a narrow range of projects such as ship design, large metal structures, facilities design, plant design, etc. (NAVEIRO, 2010).

The majority of the CAD systems are developed to help the activity of an individual designer; they are not capable to help a cooperative decision making in design and have no autonomy to identify problems or inconsistencies in projects. Commercial CAD systems are capable of pointing out certain graphical interferences, like two solids occupying the same place, but are not able to identify usability aspects as the lack of access to equipments, or the need of an additional maneuvering device to facilitate the operation of a system, for example. They do not impose constraints to a designer when he includes a tubing line passage through spaces left purposely "free" in an offshore platform, such as access openings, hatches, etc. The analysis and judgment of these situations need the designer intervention, as his intentions are not captured by the system.

\section{The development of an offshore platform project}

The design progression in the Engineering \& Construction (E\&C) sector follows standards issued by the $\mathrm{E} \& \mathrm{C}$ associations, and professionals are acquainted with the steps needed to achieve a complete description of a building. They prepare some key documents at each step of the design progression and some documents must be presented to the local authorities to have a project approved.

The workflow in the E\&C sector is very stable and well known. Building procedures are very well defined and the steps to be followed to complete a project are public domain among the E\&C community. As already argued, the initial perception of a building structure is known and the disciplines involved in the building design process are already identified. Designing a offshore platform belongs to the class of routine design, where design strategies and plans to arrive to new solutions are already known. Engineers use established procedures as frames to construct a genuine strategy tailored to the specificity of a given situation.

The organizational pattern of the E\&C sector is not vertically integrated as it is observed in the manufacturing industry. In the E\&C sector a cluster of companies take care of a contract, each company being responsible for part of the design progression. It is common to have companies involved only in some specialized portions of the project - as plumbing, structure, acoustics - and others that are responsible for the construction itself. There are also companies specialized in the quality control of the construction process. This specialization and fragmentation are typical of the E\&C sector, which can be roughly described as a network of specialized companies that take care of part of the building process or develop a subsystem of the building. This division of labour occurs in the design phase and in the construction phase as well.
An offshore oil platform is a product resulting from incremental inovations carried out along time. The conception and execution strategy of an offshore platform is to divide it in blocks made up of modules, units partially independent assembled to configure a block.

The design of an offshore platform follows the traditional sequence of product development in the naval industry, as follows. The first phase of platform design is the preliminary research in which feasibility studies take place; followed by the "conceptual project" phase, where concepts are generated and some alternatives selected for evaluation. The concepts are analyzed by the project stakeholders and sponsors according to technical and economical criteria and, once the winning alternative is defined, the process evolves to the definition phase intitled Basic Project (BP). After this, the project is detailed and several graphical and no graphical documents generated. In this article the detailing phase will be object of a deep analysis, once it is in this phase that many boundary objects are produced.

The detailing of a project is the phase where the subproblems are reconstructed which means that the partial solutions are integrated in the whole. Its focus is on the construction process and on the relationship between what was designed and how it will be manufactured. This phase aims at arriving to a complete description of the objet to be manufactured; it encompasses the final specification of materials, the selection and detailing of components and the final adjustments to be introduced in the project to fulfil operation and maintenance requirements.

The execution phase is the final phase of a project, in which the construction and assembling activities are carried out; whether in the field in the case of industrial facilities, or at the shipyard as in the case of platforms and ships. A current practice used for the construction of offshore platforms is intitled "advanced finishing" which consists of parcial delivery of the platform modules to begin, as early as possible, the construction of the blocks that will compose the platform; as well as the installation of equipment benches, components welding and other activities, which would be more difficult if carried out at a more advance stage of the construction.

\section{The case study}

The lower hull of a semi-submersible oil prospection platform was studied. This module was developed by an engineering company located in Rio de Janeiro with wide experience in naval and offshore projects. The lower hull is part of inferior part of the platform, whose main objective is to support the superior modules and guarantee the flotability of the vessel. The lower hull is made up by four pillars, linked by means of steel structures named pontoons, as illustrated in Figure 1. It comprehends the freshwater 


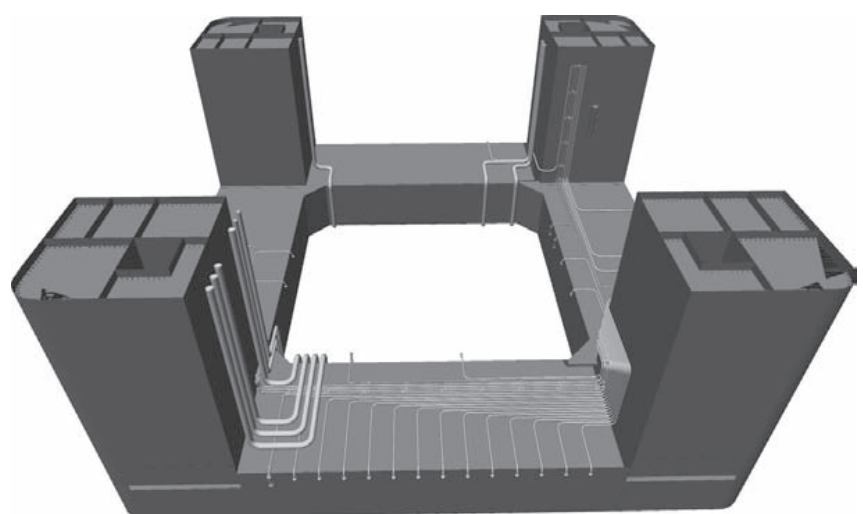

Figure 1. Lower hull 3D model.

system, diesel, ballast, sewage, pillar draining, ventilation $\&$ air conditioning, and compressed air.

One of the authors has pursued designers' activities during the detailing phase of the lower hull tubing \& piping per a period of 1 year and 18 months, by means of the participant-observation ethnographic technique. During this period of observation several boundary objects were generated and discussed by the designers involved in this activity. They were privileged elements for comprehension of the decision making process of this phase. The systematic data collection employed was similar to the one used by Wulff, Westgaard and Rasmussen (1999). The data was collected from the project documents, as well as through the designers' interviews and verbalizations carried out during the follow up of their activities.

The data collection was divided in three stages as follows:

\subsection{Stage 1: project documents analysis}

A survey on project papers was done based on a document named "Basic Design Document List". This list contains a total of 308 documents, divided by technical domains. A set of thirty four documents refered to the "piping" discipline were examined, comprising drawings, technical specifications, lists of materials and instruments, material orders, data sheets and reports. A subset of these documents were analysed comprising: General Technical Description (GTD), General Engineering Design Work Plan (GEDWP), Marine System, Piping Practice, and ET200. The last two ones are specific to "piping."

These documents were carefully read, and some parts of them were extracted. They are the ones that describe the formal organization of the project, its objectives, the scope of the work, the participants' responsibilities, and the main sub-processes related to the detailing phase. These documents represent a small fraction of the whole documentation, but they were fundamental and sufficient to understand and describe the project progression, as well as to guide the interviews conducted within the project team.

\subsection{Stage 2: interviews}

Several interviews were set up with different designers to match the following objectives:

- Acquire a general view of the project context, and the project progression as a whole.

- Understand the "piping" discipline in terms of its organization, its dynamics and realize how the project solutions are constructed.

- Recognize the objects manipulated by the "piping" technicians and the level of their knowledge about the project documentation, especifically on those that refer to human factors and ergonomics.

- Identify critical operation problems on similar platforms already in operation to check how these problems were being treated in the case studied.

\subsection{Stage 3: the designers' activities follow-up}

In this stage, it was attempted to understand how and under which perspectives some of the main actors of the project consider the final users' (operators) needs, which means how the usability dimension is integrated to the design detailing phase. This goal was achieved by the following actions:

- Identification of critical situations pointed out on platforms in operation in the field; designers involved with these issues in the detailing phase were demanded to describe how they were treating these problems in the case studied.

- Verification how documents released in the detailing phase were judged by the team of inspectors and by future users regarding usability.

- Appraisal of the compliance with final users' requirements in the design review sessions, as well as when using HAZOP "hazard and operability studies" technique is applied in the prevention of problems. HAZOP is a qualitative risk analysis technique developed from the analysis of projects with the objective of examining processes, indentifiying danger and preventing problems.

\section{The boundary objects in the detailed phase}

Activities carried out by designers and technicians in the "piping" discipline are characterised by the intense manipulation of several objects: written reports, norms, rules, component and 3D drawings, regardless if originated from the contractor or generated by the design team.

The type of objects handled varies according to the project phase. In the initial phases of the project, an intensive handling of prescriptive objects is verified like as for example: 
- Guidelines and coordination documents used by all disciplines: Contract, General Technique Description (GTD), General Engineering Design Work Plan (GEDWP), Marine System, General Arrangement Plan.

- Technical documents related to the piping domain: Diagrams (P\&ID) of all the fluids; ET-200, Piping Practice; structural drawings, sketches and safety drawings.

- Government norms and regulations are also handled, such as those of the Ministery of Labor, the Naval Classification Societies, Ports and Coastal Authority and Safety of Life at Sea (SOLAS).

Participants capture their attributions and their role in the project, identify the goals to be achieved and define the accomplishment of some generic tasks to solve problems based on objects handled in this phase. These objects are classified as close boundary objects as they leave little margin to the designers' changes, given the little potential they have to be modified.

In the intermediary phase, handling of prescriptive objects is still observed; nevertheless, a great deal of more open objects is also present. There are some examples, as the insertion of graphical items in the General Arrangement Plan, according to the information gathered from the several disciplines that intervene in this document. There are also others documents treated in this phase, like sketches, piping and instrumentation diagrams (P\&ID); equipment supplier's installation drawings, and the 3D Model. The 3D Model or electronic mock-up is the boundary object that allows the reconciliation among the several disciplines, permitting the integration of spatial argumentation in the design discourse and enables the collective decision making during design review sessions.

In the final stage of the detailing phase, we remark the supremacy of formal objects as means of integrating different domains. In this phase, the electronic mock-up is practically concluded, and the documents extracted from the 3D Model in the PDS environment are mainly the isometric drawings, spools, the piping plan, drawings that provide support to equipments and lists of materials. These are the deliverables of this phase to the execution phase that follows the detailing phase. In Figure 2 the main stages of the design progression are presented and the boundary objects handled during the detailed phase as well.

In Figure 3 two types of boundary objects are presented. A pipeline isometric drawing is shown; it is classified as closed boundary object due to difficulties of its comprehension by other participants from different domains. In the isometric drawings all the parts of a pipeline are depicted, and the location of the tubing splices and accessories is shown. The isometric drawings are used to list the materials to be purchased to the piping $\&$ tubing systems.

Figure 4 depicts the 3D model of an offshore platform. The 3D Model, or electronic mock-up, is classified as an open boundary object, an object that facilitates the reconciliation among the several disciplines, permitting the integration of spatial argumentation in the design discourse, and that enables the collective decision making during design review sessions. In the situation illustrated in Figure 4 an usability inconsistency was discovered; a valve pneumatic actuator was placed above the floor, when it should be below it.

\section{The 3D model and the design review}

In this case study the detailing of the lower hull piping system was done using a solid modeling CAD system in which components have mass properties and with parametric three-dimensional functions for modeling solids. The design activity was developed based on the concept of "model", a three dimension graphical representation that embodies

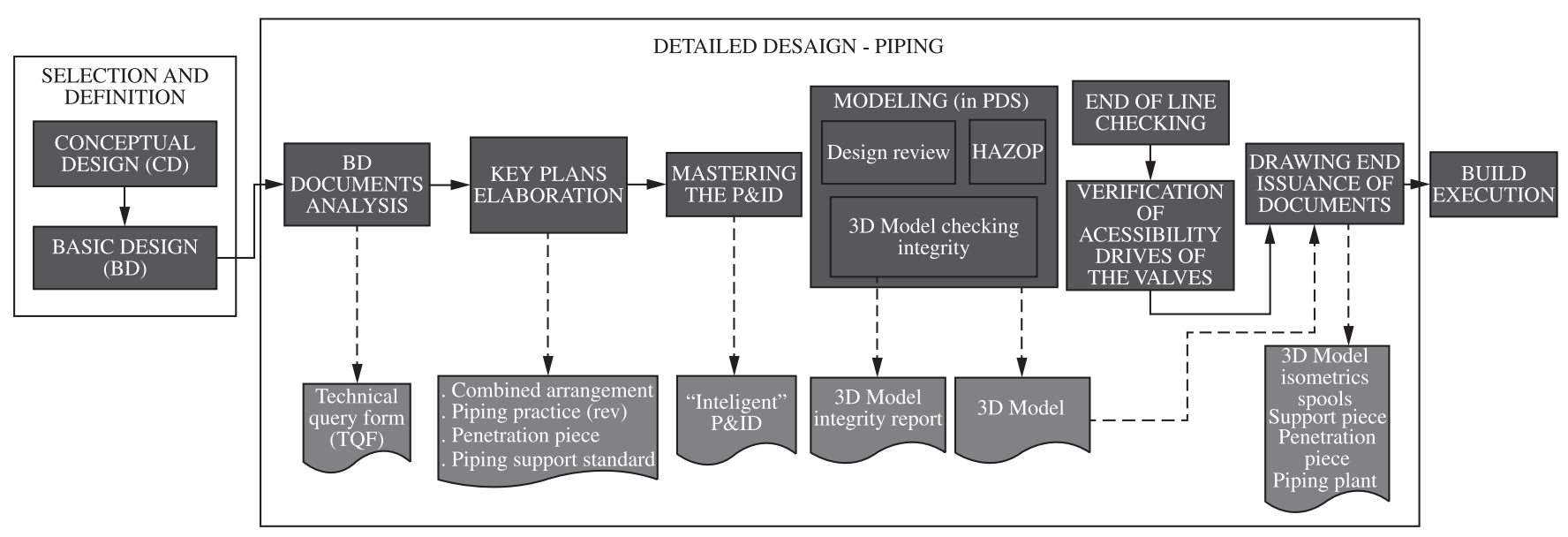

Figure 2. The design process. Emphasis in piping details. 


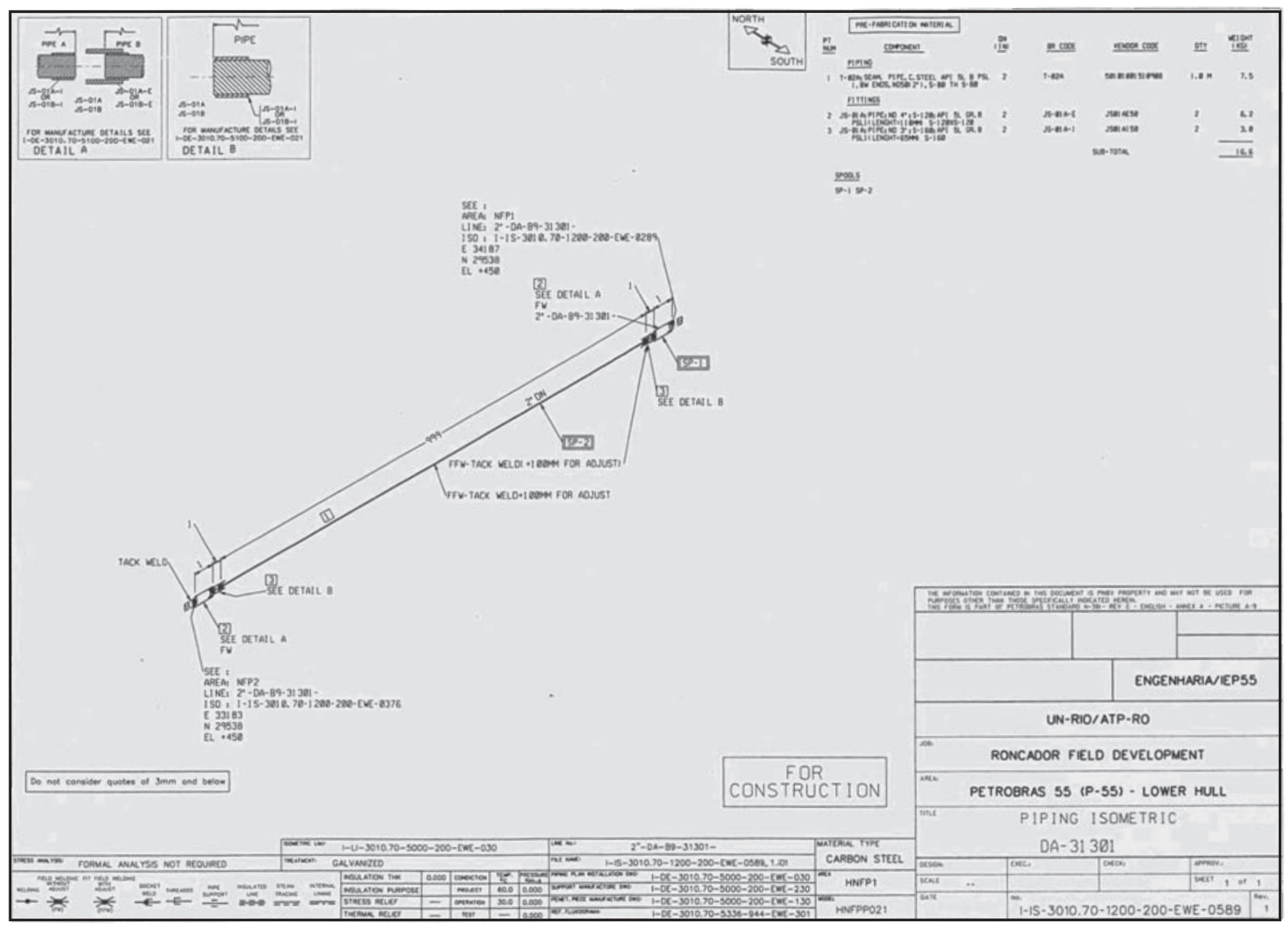

Figure 3. Isometric drawing.

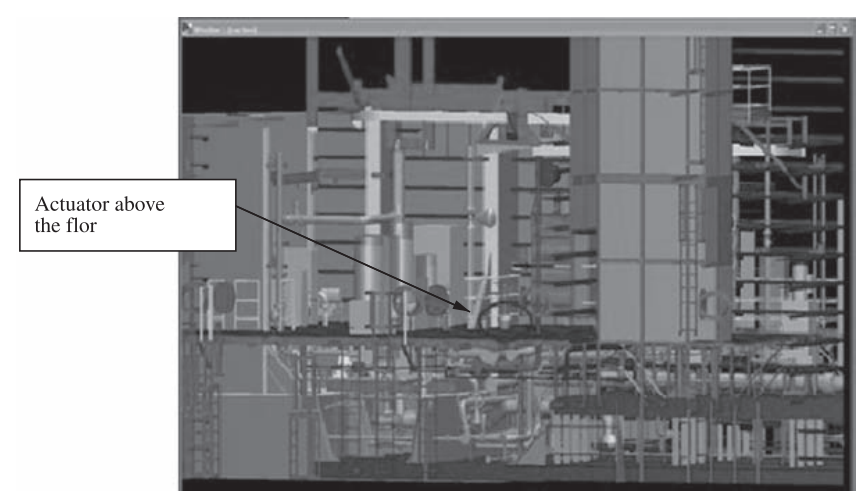

Figure 4. 3D Model inconsistency, verified in design review section.

all components of the object in a solid representation that permits the anticipation of problems that could show up during construction and assembly.

The model implementation consists of the utilization of a 3D virtual environment, intitled Plant Design System (PDS), used as repository of drawings related to the several disciplines that intervene in the lower hull project: structure, outfitting, piping, electric, mechanic, and others. The PDS can be considered as a data bank integrated to a visualization tool, with graphical and non graphical features, with the possibility to manage the product components list. These tools permit the extraction of information from the data base, such as reports and drawings from the model. One important feature of the PDS environment is that any changes made in the model are automatically updated in the drawings.

In the PDS environment designers perform their tasks completely, which means that they are defining concepts at the same time that are defining equipments, accessories, structures, etc. They use specific virtual tools as for example the Piping Design System for the piping discipline, which is an specific CAD system with all knowledge regarding piping accessories, components, piping simbology, etc. This system is integrated to the PDS databank; it enables the extraction of the isometric drawings that are sent for the execution phase carried out at the shipyard. These isometric drawings contain all the information needed to the production and assembly of the pipelines. 
One of the major advantages provided by the use of the $3 \mathrm{D}$ model is to enable the interoperability among the project disiciplines. It permits the visualization of projects in an integrated way and the consequent possibility of verifying eventual interferences among components pertaining to different domains, thus anticipating problems which would occur during the execution phase or production start-up. The use of the electronic mock-up allows to each participant create interfaces with other contexts that influence its specific universe of competence permitting participants to cross the border between subject-matters, and solving project problems through negotiation and collective decision making.

Figure 5 depicts the 3D model used in a design review session to discuss the position of valves of a piping line. This design review session had the presence of future users of the offshore platform who identified a problem in the position of a valve actuator through the electrocnic mockup. The soluction found by the interaction among partipants grounded to the electronic mock-up conveyed to a common solution: introduce an extension in the valve actuators.

It was also verified that the draining valves of the sea chest, also represented in Figure 5, needed to receive an extension device to permit their activation from the grating (floor), avoiding the displacement of the operator to the floor immediately below. This decision was very important for the platform safety, as these valves need to be activated very fast in danger situations. Designers have built their soluction based in similar situations observed in former projects. The PDS environment permits the retrieving of soluctions addopted in former projects that are reshaped to the current situation in the spirit of case-based reasoning already mentioned in this paper.

Another example of the electronic mock-up importance to anticipate design problems is the case of the positioning of the diesel system discharge valve, in Figure 6. Based on the $3 \mathrm{D}$ model, it was verified that the valve was at a height of $2.328 \mathrm{~mm}$, which implied in difficult to acess, and without any specific device provided by the Oufitting.

Differently from the P\&ID diagrams, the 3D model permits a precise visualization of the spatial relations of components and their usability. The 3D model integrates the design discourse wtih the graphical representation, and the interaction, grounded in a common context, enables participants to display abilities ahead of those displayed on their own. This means that the interactions established among participants enable knowledge to be shared and permit knowledge acquisition.

The 3D model is therefore a very important boundary object, essential to enable the sharing understanding of a project by the design team (PORTHUN; NAVEIRO; DUARTE, 2009). As already described, the potential of 3D models to anticipate problems is directly related to

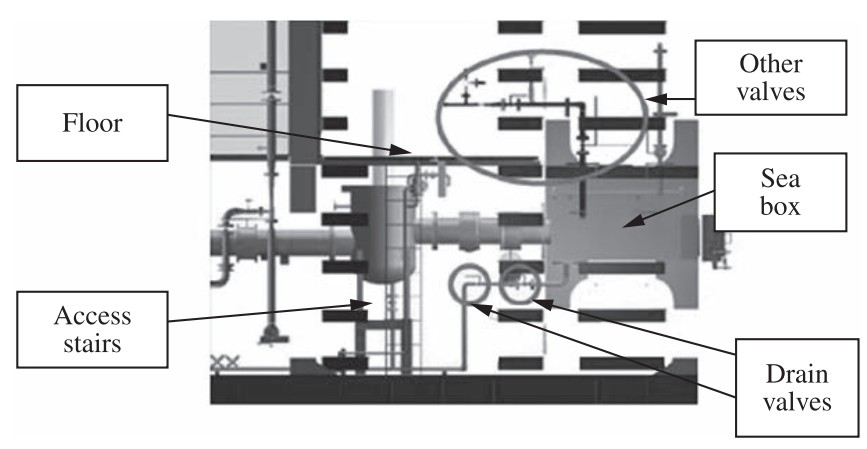

Figure 5. 3D Model. Drain valves position.

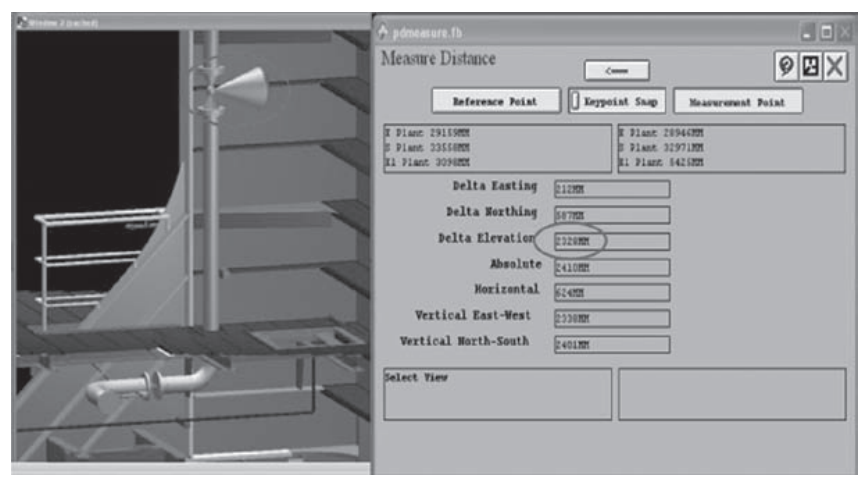

Figure 6. Discharge valve of diesel system and elevation measure (delta elevation).

the design review meetings. Such meetings need previous preparation, the soundness of design review sections is based on a careful selection of images and drawings, and on the participation of all specialists involved with the problem. This is a prerequisite to make electronic mock-ups a strong tool to build and maintain a shared conception of a problem and a means of collective decision making.

\section{Conclusions}

This article attempted to characterize the design activity in its collective dimension, showing that the design process uses several forms of visual and natural language in the conception of an artifact, and that visual language integrated to other forms of communication allows the contextualization of problems, and the translation of design soluctions to different people with different technical background.

It was described that the design process encompasses a set of intellectual activities concerned with problem solving and negotiation processes among participants, in which design discourse is one of the key factors for effective communication. It is commonplace that the negotiation processes among a design team for the solution of a problem is difficult, especially because each participant approaches 
and understands the problems within his specialization field. Individual decisions must be validated and integrated with the collective constraints that dynamically change during design progression.

It was also shown that the design process is also recursive, there is a need in keeping tracking on decisions to follow new routes or choose different conceptions. This is one of the features provided by the Plant Design System (PDS) environment used in offshore platform design, which permits the recording of the modifications that take place in the project, and the assumptions considered in decision making. These activities are enabled by attaching the design discourse to the boundary objects used in the decision process.

The role of boundary objects has been stressed as a fundamental element to improve interaction in the core of a project team, permitting the expression of different points of view, and facilitating the construction of collective action in solving problems and defining solutions as well. The boundary objects were defined and characterized through a case study in a project that have been assisted by one of the authors during eighteen months, using the ethnographic technique of participant observation.

Among the several boundary objects used along the project of a platform, an especial emphasis was placed on the electronic mock-up, a 3D model of the platform which, besides representing the product graphically, permits the extraction of geometric elements once it is carried out through a solid modeling CAD system. The electronic mock-up has permitted in meetings called "design review" to reconciliate the several fields of specialization of the participants, serving as a fundamental element to integrate the collective dimension to the individual dimension, both always present in the project activity. Design review sessions enable anticipating the solution to eventual problems, permitting project cost anticipating changes, which would cost much more if made at more advanced stage of the design progression.

As pointed before, the electronic mock-up enables cooperation and communication mechanisms that clarify the argumentation that takes place in the design process. It allows spatial argumentation to be integrated in the solution of the design problems, in the maintenance of consistency in decision-making, and keeping track of decisions as well. In this way, the design rationale can be contextualized relating construction and argumentation to each other.

Summarizing the contribution of the boundary object electronic mock-up to the design process one can state that it is a computer environment that fulfils four main goals:

- Integrates relevant knowledge to solve design problems, supporting argumentation by sharing visual information.

- Shares individual's tacit knowledge through interaction, enabling them to cross the border among different disciplines.

- Allows participants making changes in documents according to their universes of specialization and role in the project.

- Enables the design team integration fulfilling the need of a common understanding of a design problem within the team.

Computer support for teamwork in design is still in development. There are CAD systems capable to describe completely an artifact associating features from different domains to the 3D geometric model. The electronic mockup is a boundary objects that enables interaction and knowledge acquisition during the design process serving as an alternative to surpass the CAD short comings in assisting designers in integrating different constraints subject to different points of view. There are not robust integrated seamless systems embedded with knowledge capable to automatically integrate constraints related to different domains, confirming that this is a subject that needs major developments in the E\&C Sector.

\section{References}

BANNON, L.; SCHMIDT, K. CSCW: Four characters in searching for a context. In: BOWERS, J.; BENFORD, S. (Ed.). Studies in Supported Cooperative Work. Elsevier, 1991. p. 3-16.

BROWN, J. S.; DUGUID, P. Organizational learning and communities of practice: towards a unified view of working, learning and organization. Organization Science, v. 2, n. 1, p. 40-57, 1991. http://dx.doi.org/10.1287/orsc.2.1.40

BUCCIARELLI, L. An ethnographic perspective on engineering design. Design Studies, v. 9, n. 3, p. 159-168, 1988. http:// dx.doi.org/10.1016/0142-694X(88)90045-2

BUCCIARELLI, L. Designing engineers. Cambridge: The MIT Press, 1994.

CHANDRASEKARAN, B. Generic tasks as building blocks for knowledge-based systems: the diagnosis and routine design examples. The Knowledge Engineering Review, v. 3, n. 3, p. 183-219, 1988. http://dx.doi.org/10.1017/ S0269888900004458

CLANCEY, W. J. Practice cannot be reduced to theory: Knowledge, representations and change in workplace. In: BAGNARA, S.; ZUCCERMAGLIO, C.; STUCKY, S. (Eds.).Organizational Learning and Technological Change. Berlin: Springer,1995. p. 16-46.

CROSS, N. Intelligent support for communication in design teams: garment shape specifications in the knitwear industry. Design Studies, v. 21, p. 99-112, 2000.

DARSES, F.; REUZEAU, F. Participação dos Usuários na Concepção dos Sistemas e Dispositivos de Trabalho. 
In: FALZON, P. (Ed.). Ergonomia. São Paulo: Editora Blucher, 2007.

KARSENTY, L., BREZILLON, P. Cooperative problem solving and explanation. Expert Systems and Applications, v. 8, n. 4, p. 445-462, 1995. http://dx.doi.org/10.1016/09574174(94)E0035-S

KOLODNER, J. Towards an understanding of the role of experience in the evolution from novice to expert. International Journal of Man-Machine Studies, v. 19, p. 497-518, 1983. http://dx.doi.org/10.1016/S00207373(83)80068-6

MARTIN, C. La conception architecturale entre volonté politique de l'intervention technique. 1998. Tese (Doutorado em Ergonomia)-Laboratoire d'Ergonomiedu CNAM, Bordeaux, 1998.

NAVEIRO, R. The role of computer support for integrated product design. In: INTERNATIONAL CONFERENCE ON ENGINEERING DESIGN, 11., 1997, Tampere. Proceedings... Tampere: Heurista, 1997. p. 465-469.

NAVEIRO, R. Conceitos e Metodologias de Projeto. In: NAVEIRO, R., OLIVEIRA, V. (Eds.). O projeto de engenharia, arquitetura e desenho industrial. Editora da Universidade Federal de Juiz de Fora, 2001.

NAVEIRO, R.; BREZILLON, P. Knowledge and context in design for a collaborative decision making. Journal of Decision Systems, v. 12, n. 3-4, p. 253-271, 2003. http:// dx.doi.org/10.3166/jds. 12.253-270

NAVEIRO. R. A representação do produto. In: ROMEIRO, E. et al. (Eds.). Projeto do Produto. São Paulo: Elsevier, 2010.

PORTHUN, R.; NAVEIRO, R. M.; DUARTE, F. Uma proposta de caracterização da atividade de projeto e suas relações com sistemas CAD. In: CONGRESSO BRASILEIRO DE GESTÃO DE DESENVOLVIMENTO DE PRODUTO CBGDP, 7., 2009, São José dos Campos. Anais... São José dos Campos, 2009.

TANG, M. Indutive learning techniques in design process: a design concept learning system. Integrated ComputerAided Engineering, v. 8, p. 171-186, 2001.

VINCK, D. Objet-frontiere versus Objet intermediaire - vers une théorie unifiée passant par lanotion d'équipement. Laboratoire PACTE Politique - Organisations (CNRS/ Université de Grenoble) [199-?].

VINCK, D.; JEANTET, A. Mediating and commissioning objects in the sociotechnical process of product design: a conceptual approach. In: Mangement and new technology: design, networks and strategies. Proceedings from Cost A3 Workshop, Grenoble, 1995.

VINCK, D.; LAUREILLARD, P. Représenter, coordonner, attributer. Journées CSI, 1995.

VINCK, D.; LAUREILLARD, P. Everyday engineering: an ethnography of design and innovation. Cambridge: MIT Press, 2003.

VYGOTSKY, L. Mind in society: the development of higher psychological processes. Cambridge: Harvard University Press, 1978.

WEnGER, E. Communities of Practice. New York: Cambridge University Press, 1998.

WULFF, I. A.; WESTGAARD, R. H.; RASMUSSEN, B. Ergonomic criteria in large-scale engineering design. Applied Ergonomics, v. 30, p. 191-205, 1999. http://dx.doi. org/10.1016/S0003-6870(98)00029-5 